\title{
PENGGUNAAN ELEKTRODA TEMBAGA DAN SENG DENGAN ELEKTROLIT AIR LAUT UNTUK SUMBER ENERGI LAMPU LED-DIP
}

\section{THE USE OF COPPER AND ZINC WITH SEAWATER ELECTROLYTE FOR ENERGY SOURCE OF LED-DIP}

\author{
Nofrizal Hayadi Saputra ${ }^{1}$, Sugeng Hari Wisudo ${ }^{2}$, Mochammad Riyanto ${ }^{2}$, Adi Susanto ${ }^{3}$ \\ ${ }^{1}$ Program Studi Teknologi Perikanan Laut, \\ ${ }^{2}$ Departemen Pemanfaatan Sumberdaya Perikanan, \\ Fakultas Perikanan dan Ilmu Kelautan, Institut Pertanian Bogor \\ ${ }^{3}$ Program Studi Ilmu Perikanan, Fakultas Pertanian, Universitas Sultan Ageng Tirtayasa \\ Korespondensi: wisudo1966@gmail.com,nofrizalhayadisaputra@gmail.com
}

\begin{abstract}
Dual in package light emitting diode (LED-DIP) is low energy lamp used by fisherman to attract and concentrate fish. LED-DIP requires low voltage and electric current, so it can use battery as energy source. The battery alternative is seawater battery. The objectives of this study were determining the performance of seawater battery, measuring the declining rate of light intensity, counting the corrosion of seawater battery electrode after using, and measuring the shrinkage on the foam insulator after using. The method used was laboratory experiment. The voltage (V) and current $(\mathrm{mA})$ measurement were conducted simultaneously through light intensity measurement for 3 times. It was conducted with 2 hours and 12 hours duration. The voltage and current, and declining rate of light intensity in 2 hours were recorded every 10 minutes, and in 12 hours were recorded every 60 minutes. The corrosion of seawater battery electrode was calculated by photo analysis, while the shrinkage of foam insulator was measured based on the initial thickness of foam and in the last research. This research was conducted at Flum Tank Laboratory, IPB. The results showed the seawater battery generated electric energy turned on the green LED-DIP lamp of $5 \mathrm{~mm}$ for 12 hours with low voltage as much as $2.525 \mathrm{~V} / 130 \mathrm{~mA}$, the declining rate of light intensity of LED-DIP was higher than the declining rate of the voltage and current. Based on the measurements, seawater battery could be used as environmentally friendly alternative energy as energy source of LED-DIP as fish attractor lamp in liftnet fishing.
\end{abstract}

Keyword: alternative energy sources, LED-DIP, lift net fishery, seawater battery

\begin{abstract}
ABSTRAK
Light-emitting diode tipe dual in package (LED-DIP) merupakan lampu hemat energi yang banyak digunakan oleh nelayan untuk menarik dan mengkonsentrasikan ikan. LED-DIP memerlukan tegangan dan arus listrik kecil sehingga dapat menggunakan baterai sebagai sumber energinya. Salah satu alternatif adalah baterai dengan sumber energi air laut. Tujuan penelitian ini untuk menentukan kinerja baterai air laut, mengukur laju penurunan intensitas cahaya, dan menghitung korosi yang terjadi pada elektroda baterai air laut setelah penggunaan, serta mengukur penyusutan yang terjadi pada busa isolator setelah penggunaan. Metode penelitian yang digunakan adalah uji coba laboratorium. Pengukuran tegangan $(V)$ dan arus $(\mathrm{mA})$ dilakukan bersamaan dengan pengukuran laju penurunan intensitas cahaya sebanyak 3 kali pengukuran. Pengukuran dilakukan dengan durasi 2 jam dan 12 jam. Tegangan, arus, dan laju penurunan intensitas cahaya dalam durasi 2 jam dicatat setiap 10 menit. Pada durasi 12 jam dicatat dengan interval 60 menit. Korosi elektroda baterai air laut dihitung dengan analisis foto, sedangkan penyusutan busa isolator dihitung berdasarkan ketebalan awal busa dan di akhir penelitian. Penelitian dilakukan di Laboratorium Flum Tank, IPB. Hasil penelitian menunjukkan baterai air laut menghasilkan energi listrik yang menghidupkan lampu LED-DIP hijau $5 \mathrm{~mm}$ selama 12 jam dengan voltase terendah sebesar $2.525 \mathrm{~V} / 130 \mathrm{~mA}$, laju penurunan intensitas cahaya LED-DIP lebih besar dibandingkan laju penurunan tegangan dan arus. Berdasarkan pengukuran, baterai air laut dapat digunakan sebagai energi alternatif yang ramah lingkungan sebagai sumber energi LED-DIP sebagai lampu pemikat ikan pada perikanan bagan tancap.
\end{abstract}

Kata kunci: baterai air laut, LED-DIP, perikanan bagan, sumber energi alternatif 


\section{PENDAHULUAN}

LED-DIP (Light emitting diode-Dual in-line package) merupakan salah satu lampu hemat energi (Suuronen et al. 2012) yang mudah diperoleh dan banyak tersedia di pasaran dengan berbagai keunggulan. Kebutuhan daya kecil, mudah diperoleh, harga terjangkau, tersedia dalam berbagai warna, memiliki intensitas yang tinggi, mudah diaplikasikan pada bentuk desain lampu, lebih efektif dan efisien serta ramah lingkungan (Susanto 2019). Jika dibandingkan dengan lampu pendahulunya, diantaranya yaitu lampu merkuri, lampu neon, dan lampu TL (Tubular Lamp) yang biasa digunakan oleh nelayan, lampu merkuri membutuhkan energi lebih besar untuk dapat nyala serta mengeluarkan panas dalam pemakaiannya, sedangkan dari sisi harga lampu merkuri dan lampu neon mempunyai harga lebih mahal dibandingkan LED-DIP, sedangkan kelemahan pada penggunaan lampu TL yaitu biaya operasional lampu TL sangat mahal. Puspito et al. (2015) menyatakan bahwa penggunaan lampu LED-DIP (dual in-line package) pada bagan tancap menghasilkan hasil tangkapan ikan yang lebih tinggi dibandingkan dengan lampu TL. Selain itu, LED memiliki usia yang sangat panjang, lebih dari 30 ribu jam (Atmadja et al. 2015). Keunggulan tersebut menjadikannya potensial untuk digunakan sebagai lampu pemikat dan pengkonsentrasian ikan (Wisudo et al. 2002; Shen et al. 2013) pada bagan tancap. Daya yang dibutuhkan LED-DIP $5 \mathrm{~mm}$ tidak lebih dari 0,5 watt dan hanya membutuhkan arus $20 \mathrm{~mA}$. Rendahnya energi yang dibutuhkan oleh LED-DIP dapat dikombinasikan dengan sumber energi terbarukan, salah satunya penggunaan baterai air laut. Akan tetapi, terdapat beberapa kelemahan LED-DIP jika dibandingkan dengan jenis HPL, pada LED-DIP cahaya yang dihasilkannya masih kurang terang, perakitan LED cukup sulit dilakukan dan sudut pancaran cahayanya relatif sempit (Satriawan et al. 2017).

Baterai air laut merupakan baterai dengan komposisi material terdiri atas anoda (seng) dan Katode (tembaga) yang menghasilkan energi listrik dengan proses reduksi-oksidasi antara elektron yang terkandung pada air laut sebagai sumber energi dengan Zink Oksida ( $\mathrm{ZnO})$ yang terdapat pada anoda dan kupri oksida (CuO) yang terdapat pada katoda. Menurut Ilhami dan Susanti (2014) proses reduksi oksidasi terjadi karena Zinc bereaksi dengan $\mathrm{H}_{2} \mathrm{O}$. Baterai air laut sebagai sumber energi dengan komposisi elektroda $\mathrm{Zn}-\mathrm{Cu}$ telah diteliti oleh Susanto et al. (2017a; 2017b); Susanto (2019). Penggunaan Anode seng sebagai anoda dikarenakan memiliki kinerja yang lebih baik, harga lebih murah, lebih mudah diperoleh serta memiliki kandungan zink oksida yang paling tinggi dibandingkan dengan anode galvalum dan aluminium karena mampu menghasilkan tegangan dan arus rata-rata yang lebih tinggi (Susanto 2019). Selanjutnya Susanto (2019) menyatakan kombinasi anoda seng dengan katoda tembaga pada sel baterai air laut memiliki skor lebih tinggi dibandingkan jenis kombinasi bahan lainnya sehingga kombinasi seng dan tembaga layak digunakan sebagai bahan elektrode pada baterai air laut. Baterai air laut hasil penelitian Susanto (2019) mampu menghasilkan energi listrik untuk menyalakan LED-DIP pada tegangan dan arus yang stabil dengan luas permukaan elektrode $8.640 \mathrm{~cm}^{2}$. Namun demikian, pengujian skala laboratorium yang dilakukan masih memiliki kekurangan yaitu hanya dilakukan selama 120 menit. Pengujian skala laboratorium dengan durasi yang lebih lama masih diperlukan untuk menentukan efisiensi baterai air laut sebagai sumber energi lampu pemikat ikan pada bagan tancap yang umumnya berlangsung antara 8-10 jam. Selain itu, diperlukan analisis lanjutan untuk menentukan daya tahan komponen baterai air laut dan biaya yang dibutuhkan dalam pemanfaatannya sebagai sumber energi bila dibandingkan dengan penggunaan generator untuk perikanan bagan tancap. Pentingnya penelitian ini adalah agar mengetahui kemampuan baterai air laut dalam menghasilkan listrik sehingga dapat menjadi sumber alternatif energi terbarukan yang pada akhirnya akan dapat membantu bagi nelayan khususnya bagan tancap dalam menghemat biaya pada saat melakukan operasi penangkapan ikan.

Penelitian ini secara umum bertujuan untuk menentukan potensi pemanfaatan baterai air laut sebagai sumber energi lampu LED-DIP sebagai alternatif sumber energi terbarukan bagi nelayan. Secara spesifik, tujuan penelitian ini yaitu, 1) menentukan kinerja baterai air laut sebagai sumber energi lampu LED-DIP $5 \mathrm{~mm}$ yang akan dapat digunakan sebagai lampu pemikat ikan. Adapun data yang diukur adalah tegangan (V) dan arus (mA) yang dihasilkan oleh baterai air laut dengan durasi 2 jam dengan interval 
setiap 10 menit dan 12 jam dengan interval setiap 60 menit, pengukuran tegangan dan arus menggunakan multimeter, 2) mengukur laju penurunan intensitas cahaya yang menggunakan baterai air laut sebagai sumber energi. Adapun data yang diukur adalah laju penurunan intensitas cahaya pada durasi 2 jam dengan interval setiap 10 menit, dan pada durasi 12 jam dengan interval setiap 60 menit, pengukuran laju penurunan intensitas cahaya menggunakan ILT 5000 Research Radiometre (International Light Technologies, USA), dan 3) menguji kekuatan material baterai air laut yang terdiri dari seng dan tembaga serta ketahanan busa yang digunakan dalam komponen baterai air laut. Adapun data yang diukur adalah tingkat korosi yang terjadi pada elektrode baterai air laut, tingkat korosi dihitung dengan melakukan analisis foto. Sedangkan pada busa isolator diukur ketebalan awal material busa saat akan membuat baterai dan ketebalan akhir busa isolator setelah digunakan dalam penelitian, pengukuran penyusutan ketebalan busa isolator menggunakan jangka sorong.

\section{METODE PENELITIAN}

\section{Waktu dan tempat}

Penelitian skala laboratorium ini dilaksanakan pada bulan Maret-Mei 2019 di Laboratorium Teknologi Penangkapan Ikan, Departemen Pemanfatan Sumberdaya Perikanan, Fakultas Perikanan dan Ilmu Kelautan, Institut Pertanian Bogor. Pengukuran tegangan dan arus baterai, serta pengukuran laju penurunan intensitas cahaya dilakukan pada kondisi malam hari. Selanjutnya, menghitung korosi elektroda dan penyusutan busa isolator yang terjadi pada baterai air laut dilakukan pada akhir penelitian.

\section{Alat dan bahan}

Alat yang digunakan dalam penelitian ini antara lain ILT 5000 Research Radiometre (International Light Technologies, USA) untuk mengukur intensitas cahaya di udara, kamera sebagai alat merekam setiap kegiatan penelitian, lembar kerja sebagai tempat menuliskan data, alat tulis untuk mencatat data-data yang diperlukan dan multimeter untuk mengukur tegangan (V) dan arus (mA) baterai air laut. Sementara itu bahan yang digunakan yaitu lampu LED tipe DIP $5 \mathrm{~mm}$ sebagai beban untuk baterai air laut, kabel listrik untuk menghubungkan lampu dan listrik, rangkaian baterai air laut sebagai sumber energi, isolasi sebagai media perekat pada baterai air laut setelah digulung, seng sebagai material anode untuk baterai air laut, tembaga sebagai material katode untuk baterai air laut, busa isolator sebagai material pelapis atau pembungkus pada baterai air laut yang memisahkan antara anode dan katode, kabel silikon sebagai pembatas agar tidak terlalu terjadi tekanan antara anode dan katode dan baut sebagai pengikat kabel tembaga penyalur aliran listrik. Adapun model lampu LEDDIP hijau $5 \mathrm{~mm}$ dan baterai air laut yang digunakan dalam penelitian ini dapat dilihat pada Gambar 1.

Baterai air laut menggunakan bahan elektrode seng (anode) dan tembaga (katode) dengan panjang $120 \mathrm{~cm}$, lebar $36 \mathrm{~cm}$ serta ketebalan bahan 0,2 $\mathrm{mm}$ sehingga luasan elektrode yang digunakan adalah $8.640 \mathrm{~cm}^{2}$. Luas elektrode yang digunakan pada baterai disesuaikan dengan tegangan dan arus yang dibutuhkan lampu LED-DIP $5 \mathrm{~mm}$ untuk dapat menyala. Adapun total lembaran elektroda yang digunakan pada tiap 1 batrai air laut adalah 1 lembar tembaga dengan luasan $4.320 \mathrm{~cm} 2$ dan 1 lembar seng dengan luasan $4.320 \mathrm{~cm} 2$. Adapun baterai air laut yang digunakan dalam penelitian ini adalah sebanyak 5 unit untuk dapat menyalakan 1 buah lampu yang terdiri dari 6 unit LEDDIP $5 \mathrm{~mm}$, maka keseluruhan penggunaan elektroda adalah 10 lembar. Baterai air laut digulung membentuk spiral lingkaran dan selanjutnya dimasukkan ke dalam tabung PVC. Beban lampu yang digunakan LEDDIP $5 \mathrm{~mm}$ yang disusun seri sebanyak 6 unit dengan total daya satu unit LED-DIP 5 $\mathrm{mm}$ sebesar 0,3 watt, maka total daya satu batang lampu LED-DIP $5 \mathrm{~mm}$ sebesar 1,8 watt. Seluruh percobaan menggunakan air laut dengan salinitas $35 \mathrm{ppt}$ yang diperoleh dari Laboratorium Tingkah Laku Ikan, Departemen Pemanfatan Sumberdaya Perikanan, Fakultas Perikanan dan Ilmu Kelautan, Institut Pertanian Bogor.

\section{Pengumpulan, jenis, dan sumber data}

Metode penelitian yang digunakan adalah eksperimen skala laboratorium. Pengujian dilakukan dengan merangkai 5 unit baterai air laut secara seri dan diberikan beban satu rangkaian unit lampu LED- 
DIP $5 \mathrm{~mm}$ hijau. Satu unit LED tersusun atas enam buah lampu DIP yang disusun secara pararel yang dimasukkan ke dalam pipa akrilik transparan. Proses pengujian dilakukan sebanyak 3 kali ulangan dengan durasi masing-masing ulangan selama 2 jam dan 12 jam. Pada setiap ulangan dilakukan pergantian air laut dalam tabung baterai. Ekperimen dilakukan dengan cara mengukur tegangan dan arus pada baterai air laut dan mengukur laju penurunan intensitas cahaya yang dihasilkan oleh lampu LED. Data tersebut digunakan untuk mengestimasi daya tahan bahan kompenen baterai air laut sebagai sumber energi listrik untuk perikanan bagan tancap.

\section{Pengukuran tegangan (V) dan arus (mA) baterai air laut}

Pengukuran tegangan dan arus dari baterai air laut yang diberikan beban rangkaian lampu LED dilakukan menggunakan multimeter digital dengan interval yang berbeda. Pada durasi pengamatan duajam, pengukuran dilakukan setiap interval 10 menit sedangkan 12 jam berikutnya dilakukan pada interval setiap 60 menit. Rangkaian pengukuran tegangan dan arus yang dihasilkan disajikan pada Gambar 2.

\section{Pengukuran laju penurunan intensitas cahaya}

Pengukuran laju penurunan intensitas cahaya dilakukan di dalam ruangan gelap tertutup (Wisudo et al. 2002). Lampu LED yang telah disambungkan dengan baterai air laut, kemudian digantung. Setelah itu sensor ILT 5000 dipasang tegak lurus dengan jarak 1 meter dari lampu. Sebelum lampu dinyalakan dipastikan intensitas dalam ruang pengukuran adalah 0 watt $/ \mathrm{cm}^{2}$ berdasarkan hasil pengukuran pada ILT 5000. Setelah itu, lampu LED dinyalakan kemudian data intensitas yang terukur pada ILT 5000 disimpan pada setiap interval menit pengukuran. Ilustrasi pengukuran intensitas cahaya pada medium udara disajikan pada Gambar 3.
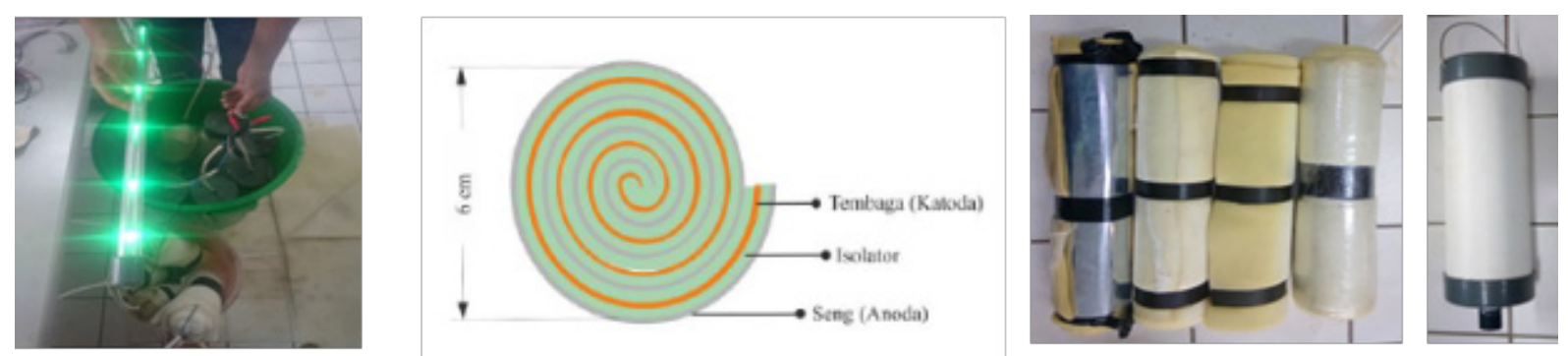

Gambar 1. Rangkaian lampu LED (kiri) dan model baterai air laut dengan spiral lingkaran untuk penelitian (tengah dan kanan)

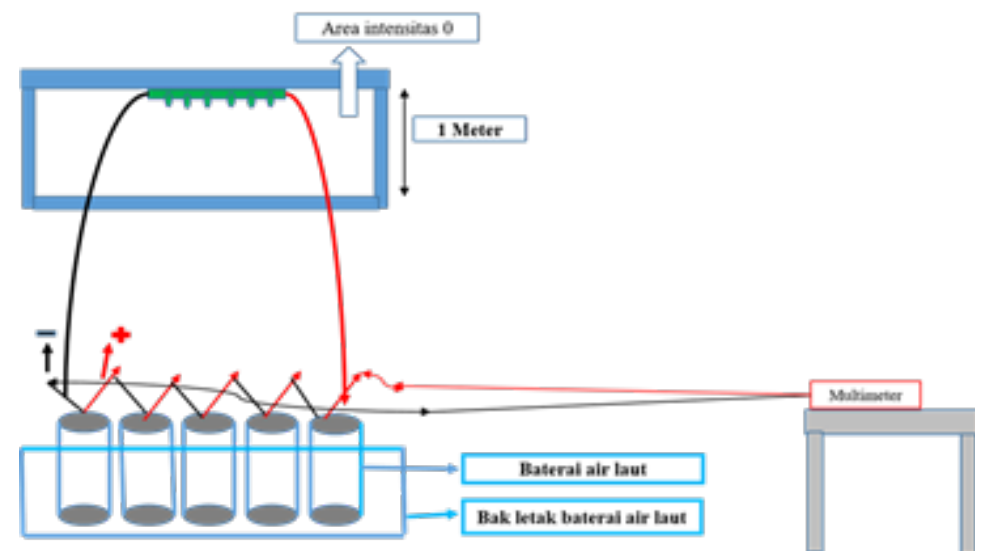

Gambar 2. Ilustrasi skema pengukuran kekuatan baterai air laut 


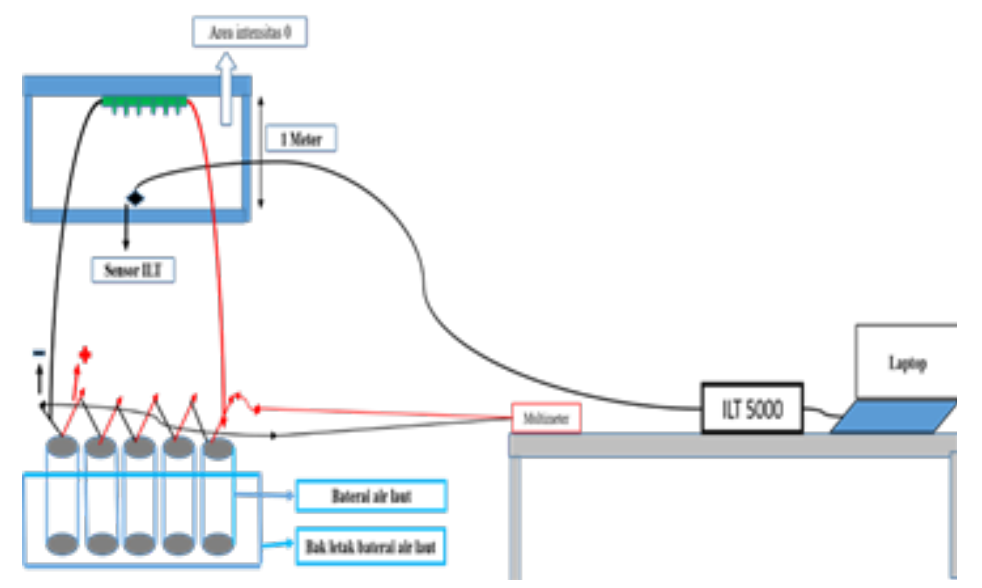

Gambar 3. Ilustrasi skema pengukuran intenstas cahaya pada medium udara

\section{Pengukuran tingkat korosi elektroda dan daya tahan busa isolator}

Data yang dikumpulkan adalah luasan lapisan elektrode yang mengalami korosi dan penyusutan ketebalan busa isolator. Persentase luasan lapisan elektrode yang mengalami korosi dihitung untuk menentukan umur teknis pemakaian masing-masing elektrode. Tingkat korosi dihitung dengan melakukan analisis foto. Penghitungan korosi pada elektroda diukur dengan menandai korosi yang terdapat pada lapisan lembaran elektroda melalui analisis foto, luasan yang terukur akan ditabulasikan, sehingga akan diketahui total persentase luasan korosi yang terdapat pada elektroda. Daya tahan material isolator pada baterai air laut ditentukan dengan menghitung perubahan ketebalan busa pada akhir penelitian, pengukuran ketebalan menggunakan alat jangka sorong.

\section{Analisis data}

\section{Kinerja baterai air laut}

Kinerja baterai air laut diukur berdasarkan nilai tegangan (V) dan arus $(\mathrm{mA})$ yang dihasilkan pada saat penelitian. Data tegangan dan arus yang diperoleh dianalisis secara deskriptif dalam bentuk grafik. Penurunan tegangan dan arus yang dihasilkan oleh baterai air laut disajikan pada interval 10 menit pengamatan untuk pengamatan selama 2 jam. Sementara itu, profil penurunan tegangan dan arus disajikan dengan interval 60 menit untuk 12 jam pengamatan.

\section{Laju penurunan intensitas cahaya}

Intensitas cahaya merupakan kekuatan penerangan dari sumber cahaya (Cayless dan Marsden 1983). Data hasil pengukuran dianalisis secara deskriptif dalam bentuk grafik penurunan cahaya berdasarkan interval menit pengamatan. Intensitas cahaya juga disajikan dalam bentuk persentase penurunan cahaya pada akhir menit pengamatan.

Tingkat korosi elektroda dan daya tahan busa isolator

Analisis persentase luasan korosi pada permukaan elektrode dilakukan menggunakan rumus luas berdasarkan bentuk pengukuran korosi yang diperoleh. Penghitungan dilakukan dalam bentuk persegi panjang dan segitiga, selanjutnya total luasan dalam bentuk persegi panjang ataupun segitiga tersebut diolah kembali dengan rumus menurut Gaspersz (1992).

Persentase luasan korosi $=(A / B) \times 100 \%$ dengan:

$A=$ Luasan korosi bidang

$B=$ Total luas elektrode

Penyusutan bobot busa isolator dihitung dengan rumus menurut Gaspersz (1992).

$$
\bar{X}=\frac{X_{0}-X_{i}}{X_{0}} \times 100 \%
$$

dengan:

$$
\begin{aligned}
& \bar{X}=\text { Besaran penyusutan } \\
& X_{O}=\text { Ketebalan awal } \\
& X_{i}=\text { Ketebalan akhir }
\end{aligned}
$$




\section{HASIL DAN PEMBAHASAN}

\section{Hasil}

\section{Tegangan keluaran}

Tegangan yang dihasilkan baterai air laut pada pengukuran pertama sebesar 2.962 V. Penggunaan baterai untuk menyalakan lampu LED-DIP selama dua jam menyebabkan tegangan keluaran mengalami penurunan sebesar $14.48 \%$ menjadi $2.533 \mathrm{~V}$. Pada awal pengukuran kedua, voltase yang dihasilkan kembali naik menjadi $2.831 \mathrm{~V}$ setelah dilakukan pergantian air laut dalam tabung baterai. Tegangan keluaran mengalami penurunan sebesar $17.66 \%$ menjadi $2.331 \mathrm{~V}$ setelah digunakan selama dua jam. Sementara itu pada pengukuran ketiga, tegangan keluaran yang diperoleh pada menit pengamatan sebesar $2.778 \mathrm{~V}$ dan mengalami penurunan sebesar $13.28 \%$ menjadi $2.409 \mathrm{~V}$ pada menit akhir pengamatan seperti disajikan pada Gambar 4a.

Pada percobaan yang dilakukan selama 12 jam, voltase yang dihasilkan baterai air laut pada masing-masing pengukuran berturut-turut sebesar 3.019 V; 2.715 V dan 2.697 V. Pada jam ke 12, tegangan pada pengukuran pertama turun sebesar 9.67\% menjadi 2.727 V. Pada pengukuran kedua dan ketiga, tegangan keluaran yang dihasilkan mengalami penurunan masing-masing sebesar $6.81 \%$ dan $6.38 \%$ menjadi 2.530 dan $2.525 \mathrm{~V}$ seperti disajikan pada Gambar $4 \mathrm{~b}$.

Arus keluaran (mA)

Arus (mA) yang dihasilkan berbanding lurus dengan tegangan (V) yang dihasilkan rangkaian baterai air laut. Semakin besar tegangan baterai, maka arus dihasilkan juga semakin tinggi. Pada durasi pengukuran dua jam, arus yang dihasilkan pada menit awal pengukuran pertama sebesar 180 $\mathrm{mA}$. Arus tersebut mengalami penurunan sebesar $28 \%$ menjadi $130 \mathrm{~mA}$ pada menit akhir pengamatan Pada pengukuran kedua, arus awal sebesar $180 \mathrm{~mA}$ dan mengalami penurunan sebesar 33.33\% menjadi $120 \mathrm{~mA}$. Arus pada menit awal pengukuran ketiga hanya $160 \mathrm{~mA}$ dan mengalami penurunan sebesar $25 \%$ menjadi $120 \mathrm{~mA}$ pada menit akhir pengamatan seperti disajikan pada Gambar 5a.

Pada pengukuran selama 12 jam, arus keluaran pada pengukuran pertama yaitu $190 \mathrm{~mA}$. Penurunan arus yang terjadi selama pengukuran sebesar $21,05 \%$ menjadi $150 \mathrm{~mA}$ pada akhir pengamatan. Pada pengukuran kedua dan ketiga nilai arus di menit awal pengamatan relatif sama yaitu $150 \mathrm{~mA}$. Penuruan yang terjadi pada pengukuran kedua dan ketiga juga sama yaitu sebesar 13,33\% sehingga pada menit akhir pengamatan diperoleh arus keluaran sebesar $130 \mathrm{~mA}$ seperti disajikan pada Gambar 5b.
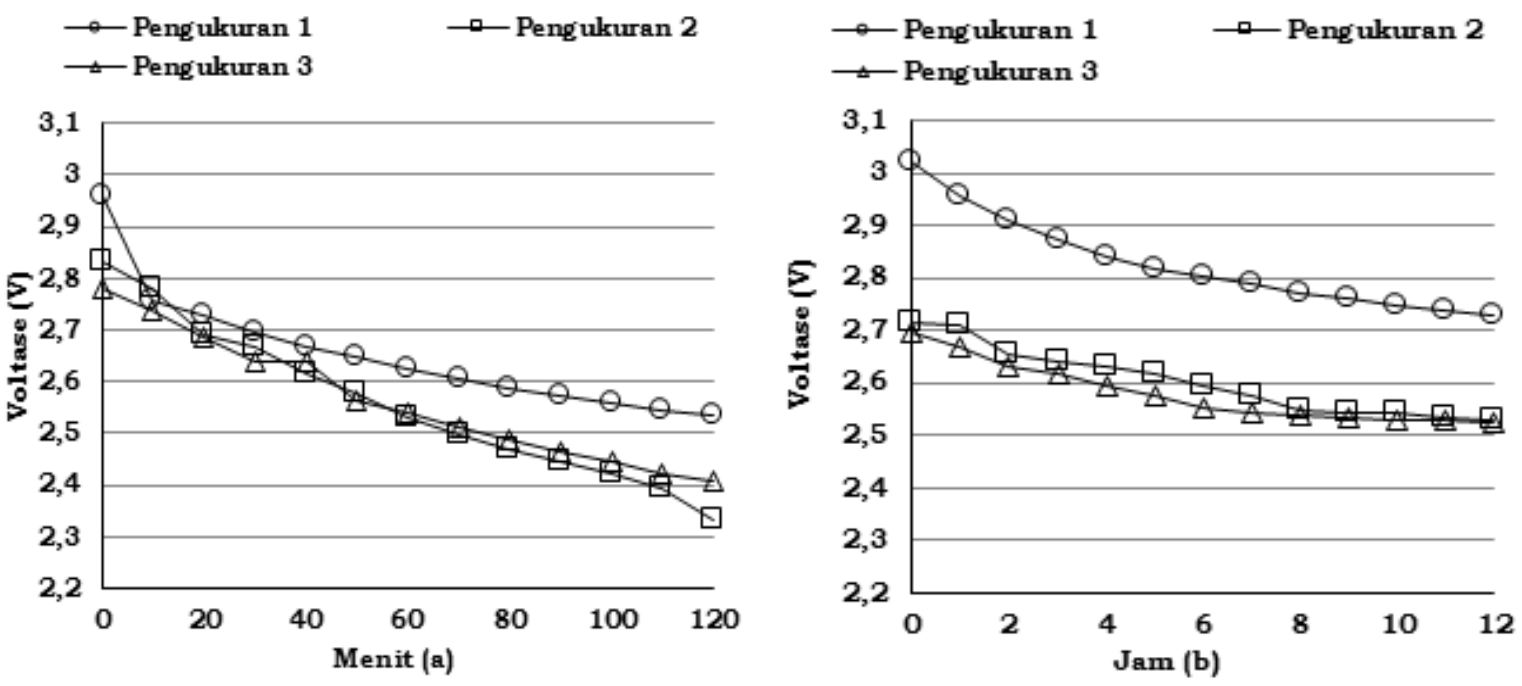

Gambar 4. Hasil pengukuran voltase baterai air laut 5 unit (a. selama 2 jam dan b. Selama 12 jam) 

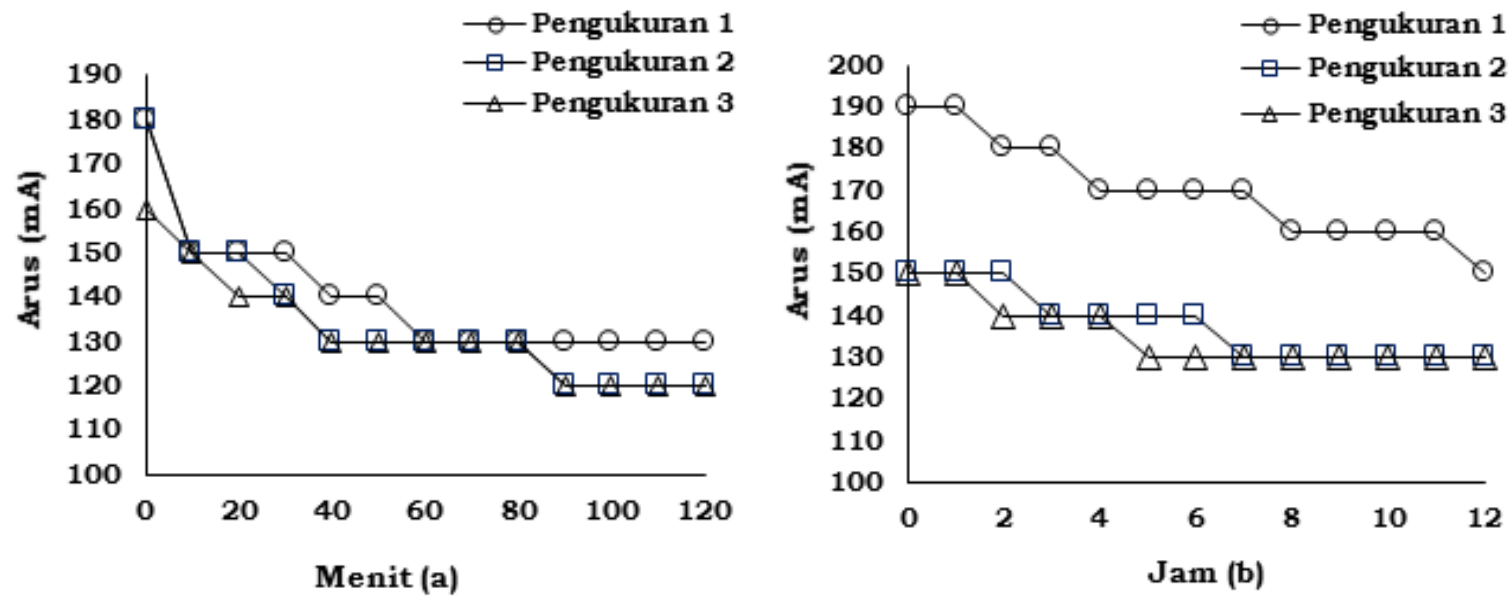

Gambar 5. Hasil pengukuran arus baterai air laut 5 unit (a. selama 2 jam dan b. Selama 12 jam)

Intensitas cahaya

Laju penurunan intensitas cahaya lampu LED-DIP dalam durasi 2 jam pengukuran disajikan pada Gambar 6a. Intensitas awal yang diperoleh pada pengukuran pertama yaitu 6,19E-04 watt/ $\mathrm{cm}^{2}$ dengan persentase penurunan sebesar $82,07 \%$ menjadi $1,11 \mathrm{E}-04$ watt $/ \mathrm{cm}^{2}$. Pada pengukuran kedua, intensitas awal yang terukur sebesar 5,99E-04 watt $/ \mathrm{cm}^{2}$ dan mengalami penurunan sebesar $98,36 \%$ menjadi 9,84E-06 pada akhir pengamatan. Sementara itu pada pengukuran ketiga, intensitas pada menit awal pengamatan adalah 5,03E-04 watt $/ \mathrm{cm}^{2}$ dengan persentase penurunan sebesar $92,47 \%$ menjadi 3,79E-05 watt $/ \mathrm{cm}^{2}$ pada menit akhir pengamatan.

Penurunan laju intensitas cahaya yang dilakukan selama 12 jam menunjukkan pola yang berbeda. Intensitas tertinggi diperoleh pada menit awal pengukuran pertama yaitu sebesar $2,16 \mathrm{E}-04 \mathrm{watt} / \mathrm{cm}^{2}$. Pada ulangan kedua intensitas pada menit awal adalah 6,49E-05 watt $/ \mathrm{cm}^{2}$, sedangkan pada ulangan ketiga intensitas awal sebesar 6,34E-05 watt $/ \mathrm{cm}^{2}$ (Gambar 6b). Pada menit akhir pengukuran pertama, kedua dan ketiga intensitas cahaya yang terukur masing-masing sebesar $7,24 \mathrm{E}-05$ watt $/ \mathrm{cm}^{2}$, 2,43E-05 watt $/ \mathrm{cm}^{2}$, dan 2,31E-05 watt/ $\mathrm{cm}^{2}$. Artinya, pada pengukuran pertama terjadi penurunan intensitas cahaya sebesar $66,48 \%$, pengukuran kedua sebesar $62,56 \%$, dan pengukuran ketiga sebesar $63,56 \%$.
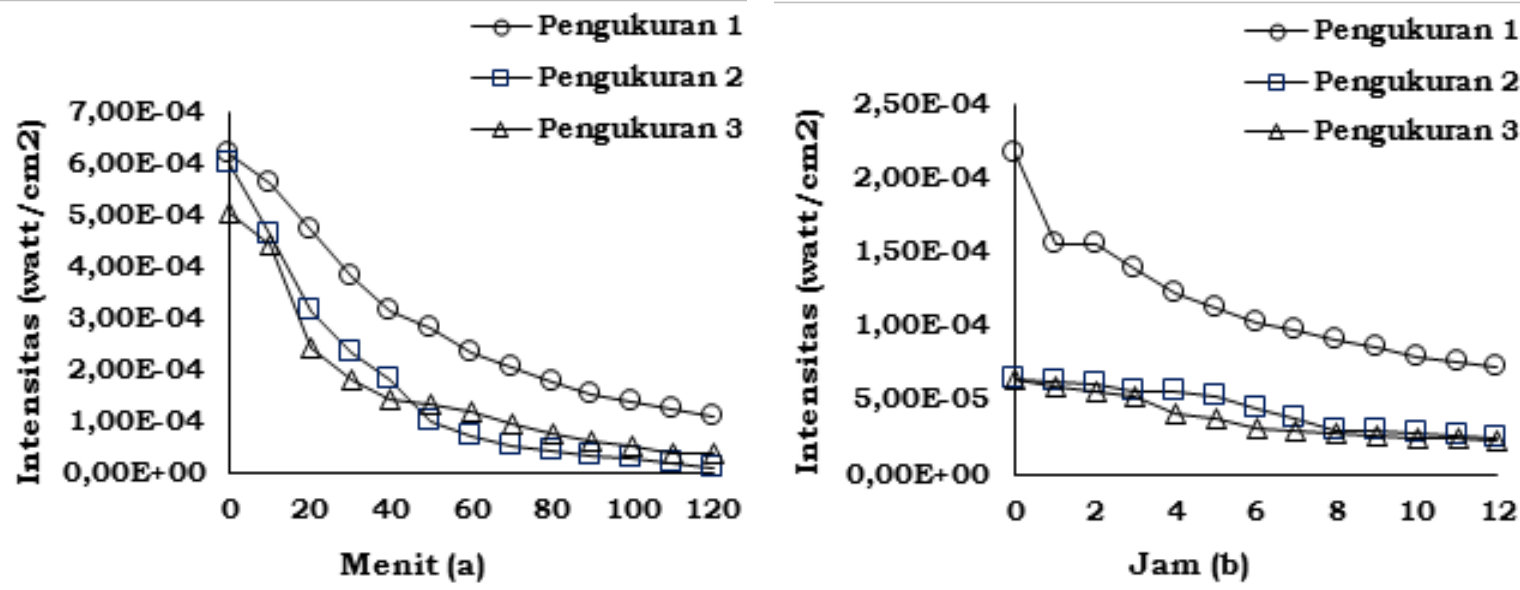

Gambar 6. Hasil pengukuran laju penurunan intensitas cahaya lampu dengan sumber energi baterai air laut (a. selama 2 jam dan b. selama 12 jam) 


\section{Korosi meterial baterai air laut}

Analisis korosi material baterai air laut dilakukan terhadap baterai air laut yang digunakan selama 15 hari. Selama penggunaan 15 hari baterai masih mampu menghasilkan energi listrik untuk menyalakan lampu LED. Setelah penggunaan, baterai direndam dalam air tawar selama \pm 12 jam dan selanjutnya disimpan hingga 70 hari. Setelah penyimpanan 70 hari, baerai air laut mengalami korosi yang menyebabkan baterai air laut tidak dapat lagi mengeluarkan tegangan (V) dan arus (mA). Pengukuran tingkat korosi dalam penelitian ini hanya dilakukan 1 kali pada saat akhir penelitian. Analisis kondisi elektrode dilakukan untuk menghitung luasan persentase korosi. Hasil analisis menunjukkan bahwa lapisan korosi terbentuk pada anode seng, sedangkan pada katode tembaga tidak terjadi korosi dan masih dapat digunakan untuk periode berikutnya. Persentase luasan korosi pada anode seng kerkisar $31,27-50,45 \%$ seperti disajikan pada Tabel 1 .

Dalam penelitian ini tembaga hanya berada pada lingkungan air laut saja sehingga proses korosi pada tembaga tidak mudah terjadi. Korosi yang terjadi terhadap anode seng diakibatkan setelah penggunaan, baterai air laut direndam selama \pm 12 jam pada air tawar tanpa dikering anginkan dan tanpa mengeluarkan air laut dari busa isolator baterai air laut, sehingga walaupun berada dalam air tawar baterai tetap berpotensi korosi karena masih ada air laut yang tersisa pada busa isolator. Korosi yang terjadi pada anode seng dalam waktu 70 hari tergolong cepat.

\section{Ketahanan busa isolator}

Jenis busa yang digunakan sebagai isolator yaitu busa lembaran (general foam/ salb foam) dengan ketebalan $0,50 \mathrm{~mm}$. Persentase penyusutan ketebalan busa isolator rata-rata sebesar $20 \%$. Penyusutan busa isolator sangat mempengaruhi kinerja baterai air laut dalam menghasilkan listrik dikarenakan penyusutan busa isolator menyebabkan katode dan anode saling menempel dan menyebabkan baterai tidak menghasilkan daya listrik. Persentase penyusutan busa sebagai isolator dapat dilihat pada Tabel 2.

Tabel 1. Persentase korosi anode seng baterai air laut

\begin{tabular}{cc}
\hline Sampel & Persentase Korosi \\
\hline 1 & $31,27 \%$ \\
2 & $36,60 \%$ \\
3 & $45,55 \%$ \\
4 & $48,50 \%$ \\
5 & $50,45 \%$ \\
\hline Rata-rata (X) & $\mathbf{4 2 , 4 7 \%}$ \\
\hline
\end{tabular}

Tabel 2. Persentase penyusutan busa (general foam/salb foam) isolator

\begin{tabular}{cccc}
\hline Sampel & Ketebalan awal $\mathbf{( m m})$ & Ketebalan akhir $\mathbf{( m m})$ & Penyusutan(mm) \\
\hline 1 & 0,50 & 0,40 & 0,10 \\
2 & 0,50 & 0,40 & 0,10 \\
3 & 0,50 & 0,40 & 0,10 \\
4 & 0,50 & 0,40 & 0,10 \\
5 & 0,50 & 0,40 & 0,10 \\
\hline
\end{tabular}




\section{Pembahasan}

Tegangan yang dihasilkan oleh baterai air laut dipengaruhi oleh jenis bahan anode yang digunakan (Ueoka et al. 2016). Susanto et al. (2017a; 2017b) menyatakan anode seng merupakan elektrode dengan kandungan $\mathrm{Zn}$ yang lebih tinggi dibandingkan aluminium, sehingga menghasilkan tegangan keluaran yang lebih besar dibandingkan aluminium. Kombinasi elektrode yang paling baik sebagai anode dan katode material baterai air laut adalah seng $(\mathrm{Zn})$ dan tembaga $(\mathrm{Cu})$. Lan et al. (2006) menyatakan kandungan $\mathrm{Zn}$ yang tinggi menyebabkan lapisan oksida lebih mudah bereaksi dengan ion klorida (C1-) dalam air laut, reaksi redoks menghasilkan aliran elektron yang lebih tinggi. Kemampuan baterai air laut dalam menghasilkan energi listrik juga dipengaruhi oleh luas permukaan efektif elektrode yang digunakan, laju perpindahan elektron, dan hambatan eksternal (Kim et al. 2016). Luas permukaan elektrode baterai air laut yang digunakan adalah $8640 \mathrm{~cm}^{2}$, terdiri dari katode tembaga dan anode seng. Tegangan dan arus keluaran tertinggi yang didapatkan yaitu 3.019 V dan 190 mA. Menurut Satriady et al. (2016) luas elektroda mempengaruhi kapasitas baterai. Kapasitas baterai dinyatakan oleh banyaknya bahan aktif pada elektrode yang dapat menghasilkan energi listrik melalui reaksi elektrokimia, semakin luas elektrode maka semakin besar kapasitas baterai, semakin luas elektrode yang digunakan maka akan memiliki lebih banyak bahan aktif yang dapat menampung elektron sehingga mampu menghasilkan energi listrik lebih besar.

Penurunan voltase dan arus yang dihasilkan baterai disebabkan juga oleh berkurangnya konsentrasi $\mathrm{NaCl}$ pada air laut yang digunakan. Unsur $\mathrm{NaCl}$ yang tinggi oleh $\mathrm{H} 2 \mathrm{O}$ diuraikan menjadi $\mathrm{Na}+$ dan $\mathrm{Cl}-$, dari proses ini muncul arus listrik. $\mathrm{NaCl}$ memiliki derajat ionisasi 1 , atau mendekati 1 dan $\mathrm{NaCl}$ termasuk larutan elektrolit kuat serta dapat terionisasi sempurna dalam air (Keenan et al. 1984). Menurut Sani (2018) besar arus dan tegangan yang dihasilkan oleh sel elektrokimia tergantung dari beberapa faktor yaitu ukuran elektroda dan kadar larutan elektrolit (garam). Artinya untuk dapat memulihkan tengangan dan arus baterai air laut salah satu syaratnya adalah melakukan penggantian larutan elektrolit.

Intesitas cahaya yang dihasilkan lampu LED-DIP $5 \mathrm{~mm}$ hijau tergantung pada voltase dan arus yang dihasilkan baterai. Intensitas yang dihasilkan berbanding lurus dengan daya yang dihasilkan rangkaian baterai air laut. Atmadja et al. (2015) menyatakan Intensitas cahaya yang dihasilkan sebanding dengan daya dan tegangan input yang masuk. Intensitas cahaya akan tinggi ketika voltase dan arus meningkat, dan menurun ketika voltase dan arus juga menurun. Selain daya dari baterai air laut, jarak pengukuran juga menjadi penentu nilai intensitas cahaya. Setiawan et al. (2015) menyatakan nilai intensitas cahaya LED memiliki hubungan linear terhadap jarak yang bervariasi, yang artinya semakin jauh jarak yang diberikan dari sumber cahaya maka semakin kecil nilai intensitas yang terukur.

Intensitas cahaya yang digunakan dalam penangkapan ikan sangat berpengaruh terhadap hasil tangkapan. Setiap jenis ikan memberikan respons, beradaptasi, dan bertingkah laku berbeda terhadap intensitas, energi, warna, dan panjang gelombang yang diterima (Bryhn et al. 2014). Sulaiman et al. (2006) menyatakan bahwa pola kedatangan ikan di sekitar sumber cahaya berbeda-beda, tergantung jenis dan keberadaan ikan di perairan. Perbedaan ini diindikasikan oleh jenis ikan yang berbeda dan kedalaman renang ikan yang berbeda tergantung dari kondisi optimum ikan tersebut. Demikian pula respon ikan berbeda terhadap cahaya mengakibatkan pola pergerakan ikan mendekati cahaya juga berbeda. Susanto et al. (2018) menyatakan preferensi ikan terhadap warna dan intensitas cahaya tertentu dapat mempengaruhi respons fisiologis retina dan tingkah laku yang terjadi selama proses penangkapan, nilai intensitas minimum (threshold) yang dibutuhkan ikan untuk mempertahankan karakteristik schooling berbeda-beda, tergantung pada spesiesnya. Torisawa et al. (2007) menyatakan bahwa nilai intensitas cahaya minimum untuk dapat mempertahankan karakteristik schooling ikan yang telah terbentuk adalah 9,4x10-13 W/ $\mathrm{cm}^{2}-1,2 \times 10$ $6 \mathrm{~W} / \mathrm{cm}^{2}$. Susanto (2019) menyatakan intensitas yang tepat dapat meningkatkan efektivitas penangkapan karena pola renang ikan target terkonsentrasi di catchable area dengan tingkat adaptasi yang optimum.

Hasil pengujian intensitas cahaya pada medium udara menunjukkan intensitas tertinggi yaitu 2,16E-04 dengan intensitas terendah 2,31E-05 watt $/ \mathrm{cm}^{2}$. 
Berdasarkan penelitian Susanto (2019) penggunaan intensitas cahaya LED-DIP hijau $5 \mathrm{~mm}$ sebesar 3,00E-05 watt $/ \mathrm{cm}^{2}$ menghasilkan area pencahayaan bagan yang masih sesuai dengan batas minimum cahaya yang dibutuhkan untuk perikanan bagan tancap. Sebaran intensitas cahaya LED-DIP hijau minimum pada area influence zone adalah sebesar 2,00E-09 watt $/ \mathrm{cm}^{2}$ dengan jarak 4 meter dari lampu dan 3,00E-05 watt $/ \mathrm{cm}^{2}$ dengan jarak 1 meter dari lampu. Berdasarkan hasil penelitian tersebut maka intensitas lampu LED-DIP hijau dengan energi baterai air laut dapat digunakan sebagai alternatif sumber cahaya pada bagan tancap. Intensitas cahaya yang dihasilkan oleh lampu LEDDIP hijau $5 \mathrm{~mm}$ dengan sumber energi air laut pada penelitian ini $156 \%$ lebih besar dibandingkan intensitas cahaya pada uji coba penangkapan yang dilakukan oleh Susanto (2019). Artinya, baterai air laut dapat digunakan pada penangkapan ikan pada bagan tancap.

Menurut Tjitro et al. (2000) umumnya laju korosi tembaga yang diperoleh tidak besar jika hanya pada satu lingkungan, misalnya lingkungan $\mathrm{NaCl}$ saja, akan tetapi korosi pada tembaga akan lebih besar jika pada lingkungan air terdapat kebersamaan dengan bahan kimia lainnya, yaitu $\mathrm{NaCl}$ dan $\mathrm{CaSO}_{4}$. Korosi yang terjadi terhadap anode seng diakibatkan setelah penggunaan perlakuan terhadap baterai air laut dengan cara merendam selama \pm 12 jam pada air tawar tanpa dikeringanginkan dan tanpa mengeluarkan air laut dari busa isolator baterai air laut, sehingga walaupun berada dalam air tawar baterai tetap berpotensi korosi karena masih ada air laut yang tersisa pada busa isolator. Korosi yang terjadi pada anode seng dalam waktu 70 hari tergolong cepat. Utomo (2015) menyatakan air laut mengandung garam akan menyebabkan korosi menjadi lebih cepat, karena memiliki sifat elektrolit yang akan memberikan suasana yang baik untuk terjadinya reaksi oksidasi-reduksi, korosi pada dasarnya merupakan reaksi logam menjadi ion pada permukaan logam yang kontak langsung dengan lingkungan berair dan oksigen.

Menurut Anggaretno et al. (2012) korosi didefinisikan sebagai proses degradasi material akibat interaksi dengan lingkungan sekitarnya. Interaksi tersebut menimbulkan reaksi korosi yang umumnya merupakan reaksi elektrokimia. Bayuseno (2009) menyatakan bahwa secara prinsip fenomena korosi hanya akan terjadi jika memenuhi empat faktor, (1) ada anode, merupakan daerah baja yang mengalami korosi (teroksidasi), (2) katode, merupakan daerah baja yang tidak terkorosi (tereduksi), (3) elektrolit, sebagai media penghantar listrik, (4) penghubung antara anode dengan katode (metallic path).

Kecepatan terjadinya korosi dipengaruhi oleh tingkat salinitas air laut. Laju korosi akan meningkat dengan naiknya salinitas air laut karena pengaruh garam-garam klorida (Sasono 2010). Menurut Anggono et al. (1999) laju korosi di lingkungan air laut sangat tinggi disebabkan pada salinitas $35 \mathrm{ppt}$ kandungan $\mathrm{Na} 10 \mathrm{~g}$ pada setiap $1 \mathrm{~kg}$ air laut dan Cl- 19,354 g pada setiap $1 \mathrm{~kg}$ air laut. Pinem (2005) menyatakan korosi logam pada lingkungan berair terjadi diakibatkan mekanisme elektro kimia yang melibatkan pelarutan logam sebagai ion. Proses seperti ini terjadi pada saat air laut memenuhi celah (crevice) yang terjadi selama pemakaian. Penurunan energi listrik yang dihasilkan baterai dipengaruhi oleh korosi yang terjadi pada anode seng. Jenis korosi yang terjadi pada anode seng yaitu korosi seragam (uniform corrosion). Hal ini ditandai serangan merata pada seluruh permukaan logam (Sidiq 2013). Untuk memperlambat korosi pada anode seng, perlakuan yang diberikan yaitu setelah baterai air laut digunakan, diharapkan baterai dibilas dengan air tawar, selanjutnya dikeringanginkan agar air tawar sisa bilasan yang masih terdapat di celahcelah baterai dapat terkuras.

Tingginya tingkat korosi yang terjadi pada anode seng membuat baterai air laut tidak dapat menghasilkan listrik. Menurut Trethewey et al. (1991) anode seng yang mengalami korosi pada air laut menyebabkan terbentuknya lapisan kulit dipermukaan lempengan yang sangat membatasi arus keluaran yang dihasilkan. Hal ini membentuk sel galvanik lokal yang menghasilkan lapisan seng hidroksida/seng karbonat yang tidak menghantarkan listrik sehingga anode seng menjadi tidak efektif. Menurut Utomo (2015) jika telah terjadi korosi pada logam, maka korosi tersebut akan dapat mempercepat proses pengaratan berikutnya.

Menipisnya busa isolator baterai air laut disebabkan baterai air laut ditekan saat akan digunakan setelah direndam pada air tawar untuk mengeluarkan air tawar yang masih tersisa. Proses penekanan ini membuat busa menjadi tipis dan robek sehingga fungsinya sebagai isolatornya 
mengalami kebocoran, arus listrik yang dihasilkan elektrode mengalir keluar tanpa ada hambatan. Tidak adanya hambatan menyebabkan arus tidak dapat mengalir dari anode ke katode dan baterai tidak dapat menghasilkan energi listrik.

Menurut Susita et al. (2012) fungsi penting dari material isolator bertujuan memisahkan bagian-bagian yang bertegangan satu sama lain, dalam hal baterai memisahkan antara katode dan anode. Selain itu, material isolator diharapkan memiliki kriteria mampu menahan beban maupun tahan terhadap korosi. Berdasarkan pengamatan, busa yang digunakan sebagai isolator pada baterai air laut tidak memiliki ketahanan yang lama terhadap tekanan antara katode dan anode, serta sensitif terhadap korosi, sehingga perlu mengganti bahan yang lebih kuat dari busa dan mampu menahan laju korosi. Menurut Wijaya (2015) bahan berserat kurang baik dijadikan sebagai penyekat listrik atau isolator, karena sifat bahan berserat yang sangat menyerap cairan dapat merusak penyekat dan daya sekat listrik akan turun. Isolator yang baik secara mekanis harus memiliki sifat kuat dielektrik dan kuat tekan, dan sifat kuat tariknya.

Berdasarkan hasil pengukuran ketebalan dan kekuatan busa isolator di awal dan setelah pemakaian. Dapat disimpulkan bahwa material busa sebagai isolator perlu diganti dengan bahan lain yang lebih kuat dan tidak mudah terpengaruh oleh korosi. Salah satu bahan yang bisa dijadikan sebagai isolator baterai air laut adalah jenis karpet meteran, dikarenakan jenis karpet ini bisa dijadikan isolator karena memiliki pori-pori sehingga mampu menyerap air laut sebagai sumber energi baterai, dan memiliki ketahanan material yang kuat dibandingkan busa, serta jenis karpet tersebut mudah didapatkan meskipun harga dari material tersebut sedikit lebih tinggi dibandingkan dengan harga busa. Akan tetapi, memiliki masa pemakaian yang lebih panjang dibandingkan busa lembaran dengan ketebalan 0,50 $\mathrm{mm}$. Berdasarkan hasil pengukuran terhadap semua parameter arus dan tegangan listrik, intensitas yang dihasilkan dari rangkaian baterai air laut yang diteliti, baterai air laut ini dapat digunakan sebagai sumber energi alternatif untuk menyalakan lampu LEDDIP yang dapat diimplementasikan pada perikanan lampu, khususnya perikanan bagan tancap.

\section{KESIMPULAN DAN SARAN}

\section{Kesimpulan}

1. Baterai air laut dengan komposisi katode tembaga dan anode seng dapat menghasilkan listrik untuk menghidupkan lampu LED-DIP hijau $5 \mathrm{~mm}$ selama 12 jam sebagai lampu pemikat ikan pada bagan tancap.

2. Laju penurunan intensitas cahaya lampu LED-DIP $5 \mathrm{~mm}$ hijau lebih besar dibandingkan laju penurunan tegangan listrik. Namun, intensitas tersebut dapat digunakan dalam penangkapan ikan pada bagan tancap.

\section{Saran}

1. Disarankan dalam penggunaan baterai air laut pada lampu LED-DIP pemikat ikan untuk setiap 2 jam baterai diangkat keatas permukaan air laut agar air laut dapat berganti secara sempurna sehingga energi listrik yang dihasilkan kembali maksimum

2. Setelah penggunaan baterai selama 70 hari disarankan untuk mengganti material anode baterai air laut yaitu seng dan busa isolator untuk mencegah korsleting agar baterai kembali bisa menghasilkan tegangan dan arus maksimum.

\section{DAFTAR PUSTAKA}

Anggaretno G, Rochani I, Supomo H. 2012. Analisa Pengaruh Jenis Elektroda terhadap Laju Korosi pada Pengelepasan Pipa API 5L grade X65 dengan Media Korosi $\mathrm{FeCl}_{3}$. J Teknik. 1(1): 124-128.

Anggono J, Tjitro S, Palapessy VR. 1999. Studi Perbandingan Kinerja Anoda Korban Paduan Aluminium dengan Paduan Seng dalam Lingkungan Air Laut. Jurusan Teknik Mesin, Fakultas Teknologi Industri, Universitas Kristen Petra.

Atmadja MD, Kristiana HM, Soelistianto FA. 2015. Pengaruh Tegangan dan Frekuensi terhadap Intensitas Cahaya pada Lampu Pendar Elektronik. PROSIDING SENTRINOV Vol. 001. ISSN: 2477-2097.

Bayuseno AP. 2009. Analisa Laju Korosi pada Baja untuk Material Kapal 
dengan dan Tanpa Perlindungan Cat. Jurnal ROTASI. 11(3): 32-37.

Bryhn AC, Königson SJ, Lunneryd SG, Bergenius MAJ. 2014. Green Lamps as Visual Stimuli Affect the Catch Efficiency of Floating Cod (Gadus morhua) Pots in the Baltic Sea. Fisheries Research. 157: 187-192.

Cayless MA, Marsden AM. 1983. Lamps and Lighting. 3rd Edition London(UK): Edward Arnold (Publisher).

Gaspersz V. 1992. Teknik Analisis dalam Penelitian Percobaan. Tarsito. Bandung.

Ilhami MR, Susanti D. 2014. Pengaruh Massa $\mathrm{Zn}$ dan Temperatur Hydrotermal terhadap Struktur dan Sifat Elektrik Material Graphene. Jurnal Teknik Pomits. 3(2): 2337-3539.

Keenan, Kleinfelter Wood. 1984. Kimia untuk Universitas Edisi Keenam Jilid 1. Jakarta: Erlangga.

Kim JK, Mueller F, Kim H, Jeong S, Park JS, Passerini S, Kim Y. 2016. Ecofriendly Energy Storage System: Seawater and Ionic Liquid Electrolyte. ChemSusChem. 9: 42-49.

Lan CJ, Chin TS, Lin PH, Perng TP. 2006. Zn-Al Alloy as A New Anode-metal of A Zinc-air Battery. Journal of New Materials for Electrochemical Systems. 9: 27-32.

Pinem MD. 2005. Korosi dan Rekayasa Permukaan. Jurnal T.eknik SIMETRIKA. 4(1): 301-306.

Puspito G, Thenu EM, Julian D, Tallo I. 2015. Utilization of Light-Emitting Diode Lamp on Lift Net Fishery. AACCL Bioflux. 8(2): 159-167.

Sani A. 2018. Analisa Baterai Air Asin dengan Elektroda Tembaga dan Aluminium. Jurusan Teknik Elektro [Skripsi]. Fakultas Teknik Universitas Muhammadiyah. Surakarta.

Sasono JE. 2010. Efektivitas Penggunaan Anoda Korban Paduan Aluminium pada Pelat Baja Kapal Aisi E 2512 terhadap Laju Korosi di dalam Media Air Laut. Program Studi Magister Teknik Mesin. Program Pascasarjana. Universitas Diponegoro. Semarang.

Satriady A, Alamsyah W, Saad AH, Hidayat S. 2016. Pengaruh Luas Elektroda terhadap Karakteristik Baterai Lifepo ${ }^{4}$. Jurnal Material dan Energi Indonesia. 6(2): 43-48.

Satriawan SE, Puspito G, Yusfiandayani R. 2017. Introduksi High Power LED pada Perikanan Bagan Tancap.
Jurnal Teknologi Perikanan dan Kelautan. 8(1): 49-58. ISSN 20874871.

Setiawan F, Sulistiyanti SR, Ageng Sadnowo. 2015. Analisis Pengaruh Medium Perambatan terhadap Intensitas Cahaya Lacuba (Lampu Celup Bawah Air). Jurnal Rekayasa dan Teknologi Elektro. 9(1): 21-29.

Shen SC, Kuo CY, Fang MC. 2013. Design and Analysis of An Underwater White LED Fish-Attracting Lamp and its Light Propagation. International Journal of Advanced Robotic Systems. 10(183): 1-10. DOI: 10.5772/56126.

Sidiq MF. 2013. Analisa Korosi dan Pengendaliannya. Jurnal Foundry. 3(1): 25-30.

Sulaiman M, Jaya I, Baskoro MS. 2006. Studi Tingkah Laku Ikan pada Proses Penangkapan dengan Alat Bantu Cahaya: Suatu Pendekatan Akustik. Indonesia J. Mar. Sci. 11(1): 31-36.

Susanto A, Baskoro MS, Wisudo SH, Riyanto M, Purwangka F. 2017a. Performance of $\mathrm{Zn}-\mathrm{Cu}$ and $\mathrm{Al}-\mathrm{Cu}$ Electrodes in Seawater Battery at Different Distance and Surface Area. International Journal of Renewable Energy Research. 7: 298-303.

Susanto A, Baskoro MS, Wisudo SH, Riyanto M, Purwangka F. 2017b. Seawater Battery with Al-Cu, Zn-Cu, Gal-Cu Electrodes for Fishing Lamp. International Journal of Renewable Energy Research. 7: 1857-1868.

Susanto A, Baskoro MS, Wisudo SH, Riyanto M, Purwangka F. 2018. Penentuan Warna dan Intensitas Lampu Light Emitting Diode (LED) yang Optimum pada Penangkapan Ikan Selar Kuning (Selaroides leptolepis) untuk Perikanan Bagan Tancap. Marine Fisheries. 9(2): 145-155.

Susanto A. 2019. Pengembangan Teknologi Pencahayaan untuk Perikanan Lift Net yang Hemat Energi dan Ramah Lingkungan. Disertasi. Bogor(ID): Institut Pertanian Bogor.

Susita RML, Sudjatmoko BA, Sujitno T, Siswanto B, Wirjoadi. 2012. Pemilihan Jenis Material Elektroda Sumber Elektron Katoda Plasma. Prosiding Pertemuan dan Presentasi Ilmiah Teknologi Akselerator dan Aplikasinya. 14: 166-176. ISSN: 1411-1349.

Suuronen P, Chopin F, Glass C, Løkkeborg S, Matsushita Y, Queirolo D, Rihan D. 
2012. Low Impact and Fuel Efficient Fishing-Looking Beyond The Horizon. Fis Res. 119-120: 135-146.

Tjitro S, Anggono J, Anggorowati AA. 2000. Studi Perilaku Korosi Tembaga dengan Variasi Konsentrasi Asam Askorbat (Vitamin C) dalam Lingkungan Air yang Mengandung Klorida dan Sulfat. Jurnal Teknik Mesin. 2(1): 62-67.

Trethewey KR, Chamberlain J. 1991. Korosi untuk Mahasiswa Sains dan Rekayasa, PT. Gramedia Pustaka Utama, Jakarta.

Torisawa S, Takagi T, Fukuda H, Ishibhasi Y, Sawada Y, Okada T, Miyashita S, Suzuki K, Yamane T. 2007. Schooling Behaviour Andretinomotor Response of Juvenile Pacific Bluefin Tuna Thunnus orientalisunder Different Light Intensities. Journal of Fish Biology. 71: 411-420.

Ueoka N, Sese N, Sue M, Kouzuma A, Watanabe K. 2016. Sizes of Anode and Cathode Affect Electricity Generation in Rice Paddy-field Microbial Fuel Cells. Journal of Sustainable Bioenergy Systems. 6: 10-15.

Utomo S. 2015. Pengaruh Konsentrasi Larutan $\mathrm{NaNO}_{2}$ sebagai Inhibitor terhadap Laju Korosi Besi dalam Media Air Laut. Jurnal Teknologi. 7(2): 93-103.

Wijaya IK. Buku Ajar Material Teknik Elektro. Jurusan Teknik Elektro dan Komputer, Fakultas Teknik Universitas Udayana.

Wisudo SH, Sakai H, Takeda S, Akiyama S, Arimoto T, Takayama T. 2002. Total Lumen Estimation of Fishing Lamp by Means of Rousseau Diagram Analysis with Lux Measurement. Fisheries Science/J. Fish Sci. 68: 479-480. 